\title{
Chiral Polyamides Having L-Glutamyl Residue as a Component
}

\author{
Yoshimi Ikeuchi $^{1}$, Masakazu Yoshikawa ${ }^{1 *}$, Hidekazu Yoshida ${ }^{2}$, Hiroki Yamanishi ${ }^{2}$, Shinichi Sakurai $^{2}$ \\ ${ }^{1}$ Department of Biomolecular Engineering, Kyoto Institute of Technology, Matsugasaki, Kyoto, Japan \\ ${ }^{2}$ Department of Macromolecular Science and Engineering, Kyoto Institute of Technology, Matsugasaki, Kyoto, Japan \\ Email: * masahiro@kit.ac.jp
}

Received August 2, 2012; revised September 6, 2012; accepted September 16, 2012

\begin{abstract}
Polyamides with chiral environment were obtained from aromatic diamine, 1,3-phenylenediamine (1,3-PDA) or 1,4phenylenediamine (1,4-PDA), and N- $\alpha$-benzoyl-L-glutamic acid (Benzoyl-L-Glu). The optical rotation $\left([\alpha]_{\mathrm{D}}\right)$ for 1,3PDA-Benzoyl-L-Glu was determined to be $3.7 \mathrm{deg} \mathrm{cm}^{2} \mathrm{~g}^{-1}$, while that for 1,4-PDA-Benzoyl-L-Glu to be $9.7 \mathrm{deg} \mathrm{cm}^{2} \mathrm{~g}^{-1}$. 1,3-PDA-Benzoyl-L-Glu showed adsorption selectivity toward D-Glu and its adsorption selectivity was determined to be 1.68. Contrary to this, 1,4-PDA-Benzoyl-L-Glu showed adsorption selectivity toward L-Glu and the adsorption selectivity toward L-Glu was determined to be 1.33 . From those results, those two types of chiral polyamide are expected to applicable to chiral separation or chiral recognition.
\end{abstract}

Keywords: Adsorption Selectivity; Chiral Polyamide; Glutamyl Residue; Polyamide; Surface Plasmon Resonance (SPR) Spectroscopy

\section{Introduction}

Chirality plays an important role in biological processes $[1,2]$. A given enantiomer and the corresponding antipode often exhibit different pharmacological effects. It is often observed that a drug enantiomer gives the desired effect whereas the antipode does not give the desired pharmacological effect or exhibit toxicity. From this, the production of enantiomerically pure compounds is an important processes in various industries, involving pharmaceuticals, agrochemicals, fragrances, food additives, and so forth.

Among various separation methods, chiral separation with membranes is promising way since membrane separation can be carried out continuously under mild conditions. In addition to this, membrane separation is economically and ecologically competitive to other separation methods since membrane separation, excepting pervaporation, can be operated without phase transition. From articles on chiral separation by using membrane [3-6], there can be found chiral recognition sites or chiral environments in membranes or membrane separation processes.

The authors' research group studied molecularly imprinted polymers [7-11], polymeric materials bearing amino acid residues [12-16], and natural polymers [17-19] as membrane materials for chiral separation. In the pres-

${ }^{*}$ Corresponding author. ent study, chiral polyamides were synthesized adopting $\mathrm{N}-\alpha$-benzoyl-L-glutamic acid (Benzoyl-L-Glu-OH) as a chiral building block and 1,3-phenylenediamine (1,3PDA) or 1,4-phenylenediamine (1,4-PDA) as diamine component, which is expected to give a more rigid chiral polyamide than $4,4^{\prime}$-diaminodiphenylmethane (DADPM) [13].

\section{Experimental}

\subsection{Materials}

N- $\alpha$-Benzoyl-L-glutamic acid (Benzoyl-L-Glu-OH), triphenyl phosphite (TPP), anhydrous $\mathrm{LiCl}$, D-glutamic acid (D-Glu), L-glutamic acid (L-Glu), 1,1,1,3,3,3-hexafluoro2-propanol (HFIP) and sodium azide (fungicide) were obtained from commercial sources and used as received. 1,3-Phenylenediamine (1,3-PDA) was purified by crystallization from diethyl ether [20] and 1,4-phenylenediamine (1,4-PDA) by sublimation under reduced pressure [21]. 1-Methyl-2-pyrrolidinone (NMP), pyridine (Py), and N,N-dimethylformamide (DMF) were purified by usual methods [22]. Water purified with an ultrapure water system (Simpli Lab, Millipore S. A., Molsheim, France) was used.

\subsection{General Polycondensation}

Requisite amounts of chemicals were placed in a reaction 
flask fitted with a condenser and thermometer. The mixture was magnetically stirred at $80^{\circ} \mathrm{C}$ for $3 \mathrm{~h}$. The resulting viscous solution was poured into methanol under rapid stirring, and the prescribed product was washed with methanol and dried in vacuo for $3 \mathrm{~d}$.

\subsection{Chracterizartion of the Chiral Polyamides}

The inherent viscosity was determined with an Ubbelohde viscometer at a concentration of $5.0 \times 10^{-3} \mathrm{~g} \mathrm{~cm}^{-3}$ in HFIP at $25^{\circ} \mathrm{C}$. The IR spectra were recorded by using a Perkin-Elmer Spectrum GX; 64 scans at a resolution of $4 \mathrm{~cm}^{-1}$ were collected with a membrane prepared from HFIP solution. The ${ }^{1} \mathrm{H}$ NMR (500 MHz) spectrum was recorded in 1,1,1,3,3,3-HFIP- $\mathrm{d}_{2}$ using a Bruker DRX500 with tetramethylsilane (TMS) as an internal standard. The thermal stability of the polymer was evaluated on a Hi-Res Modulated TGA 2950 (TA instruments) under nitrogen at a heating rate of $10^{\circ} \mathrm{C} \mathrm{min}$. Differential scanning calorimetry (DSC) was performed with Shima$\mathrm{dzu}$ DSC-60. The heating rate was fixed to be $20^{\circ} \mathrm{C} \mathrm{min}^{-1}$ and the sample was purged with nitrogen at a flow rate of $50 \mathrm{~cm}^{3} \mathrm{~min}^{-1}$. Tensile stress-strain measurement was performed with TENSILON/UTM-II-5H (Orientec) with a rectangular-shaped film (5 $\mathrm{mm}$ wide), clamped between a pair of chucks, which were $15 \mathrm{~mm}$ apart in the unstretched state. The sample thickness was around 20 $\mu \mathrm{m}$. Obtained results were averaged over 10 film samples. The specific rotations were obtained with Horiba SEPA200 polarimeter at $589 \mathrm{~nm}$ at ambient temperature in DMF.

\subsection{Adsorption Selectivity}

The adsorption selectivity of the prepared polyamides was studied as follows; a gold-deposited glass plate was immersed in a $1.0 \times 10^{-5} \mathrm{~mol} \mathrm{dm}{ }^{-3}$ solution of 1-octanthiol in ethanol for $30 \mathrm{~min}$ at ambient temperature prior to the film preparation. The film was prepared by spin-casting a $1.0 \mathrm{~g} \mathrm{dm}^{-3}$ HFIP solution of the polyamide onto the pre-treated gold-deposited glass plate. The rotation speed for spin casting was $3000 \mathrm{rpm}$.

The adsorption selectivity of the prepared film toward racemic Glu was evaluated by surface plasmon resonance (SPR) spectroscopy. The change in incident angle $(\Delta \theta)$ responding to the addition of substrate was recorded on the SPR apparatus (SPR670S, Nippon Laser and Electronics Laboratory). During the measurement, $0.02 \mathrm{wt} \%$ $\mathrm{NaN}_{3}$ aqueous buffer was passed over the film surface at $5 \mathrm{~mm}^{3} \mathrm{~min}^{-1}$. The flow was periodically replaced with solutions of same buffer containing D-glutamic acid (DGlu) or L-glutamic acid (L-Glu). The experiment was carried out at $27^{\circ} \mathrm{C}$.

\section{Results and Discussion}

\subsection{Polycondensation}

In the previous studies [12-14], chiral polyamides were prepared by means of TPP so that carboxylic acid could be activated to react with amino groups. In the present study, similar polycomdensation reaction method was adopted to obtain chiral polyamides from N- $\alpha$-benzoylL-glutamic acid (Benzoyl-L-Glu-OH) and 1,3-phenylenediamine (1,3-PDA) or 1,4-phenylenediamine (1,4PDA). In the previous study [13], the chiral polyamide was prepared from Benzoyl-L-Glu-OH and 4,4'-diaminodiphenylmethane (DADPM). As described in the introduction, chiral polyamides obtained in the present study were expected to show more rigid and more thermally stable ones than the previous one, DADPM-Benzoyl-L-Glu, which was obtained from DADPM and Benzoyl-L-Glu-OH [13].

The polycondensation scheme is shown in Figure 1. In the IR spectra, those two types of polyamide gave the amide I band at $1645 \mathrm{~cm}^{-1}$.

${ }^{1} \mathrm{H}$ NMR spectrum for 1,3-PDA-Benzoyl-L-Glu is shown in Figure 2 and that for 1,4-PDA-Benzoyl-L-Glu in Figure 3. From Figures 2 and 3, it can be confirmed that the amino protecting group of benzoyl moiety was preserved in those polyamides. The IR and ${ }^{1} \mathrm{H}$ NMR spectra led to the conclusion that the expected polyamides were obtained from Benzoyl-L-Glu-OH and 1,3PDA or 1,4-PDA. However, stereo regularity of those two types of chiral polyamide was hardly determined.

The optimum reaction conditions for polycondensation for those polyamides were determined by using viscosity of polymer solution as an index. The results of polycondensation reaction on various monomer concentrations for 1,3-PDA-Benzoyl-L-Glu are summarized in Table $\mathbf{1}$ and those for 1,4-PDA-Benzoyl-L-Glu in Table 2. From tables, the suitable monomer concentrations for the preparation of those two types of polyamide were determined to be $4.00 \times 10^{-1} \mathrm{~mol} \mathrm{dm}^{-3}$.

\subsection{Thermal Properties}

Figure 4 shows thermogravimetric analysis (TGA) thermographs for the present polyamides. The change of diamine component from DADPM to 1,3-PDA or 1,4PDA led to enhance thermal stability. The degradation temperatures for the present polyamides were over $285^{\circ} \mathrm{C}$, whereas that for DADPM-Benzoyl-L-Glu to be $155.7^{\circ} \mathrm{C}$. The adoption of diamine component of 1,3-PDA or 1,4PDA instead of DADPM might make obtained polyamides less flexible. As a result, the thermal stability of the present polyamides was enhanced [23].

Figure 5 displays DSC thermographs of the polyamides. The glass transition temperatures were determined 


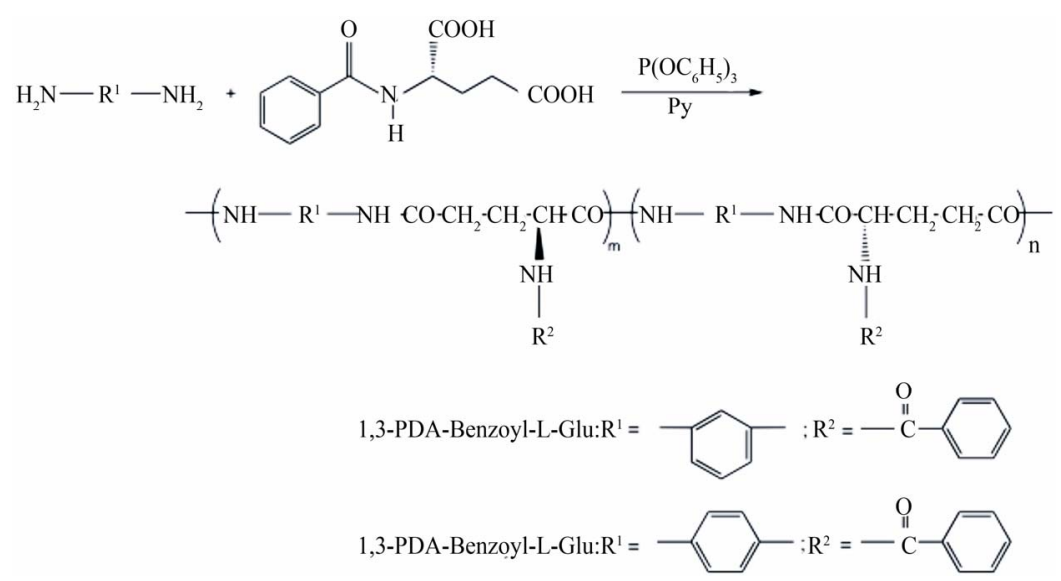

Figure 1. Synthetic scheme of chiral polyamides.

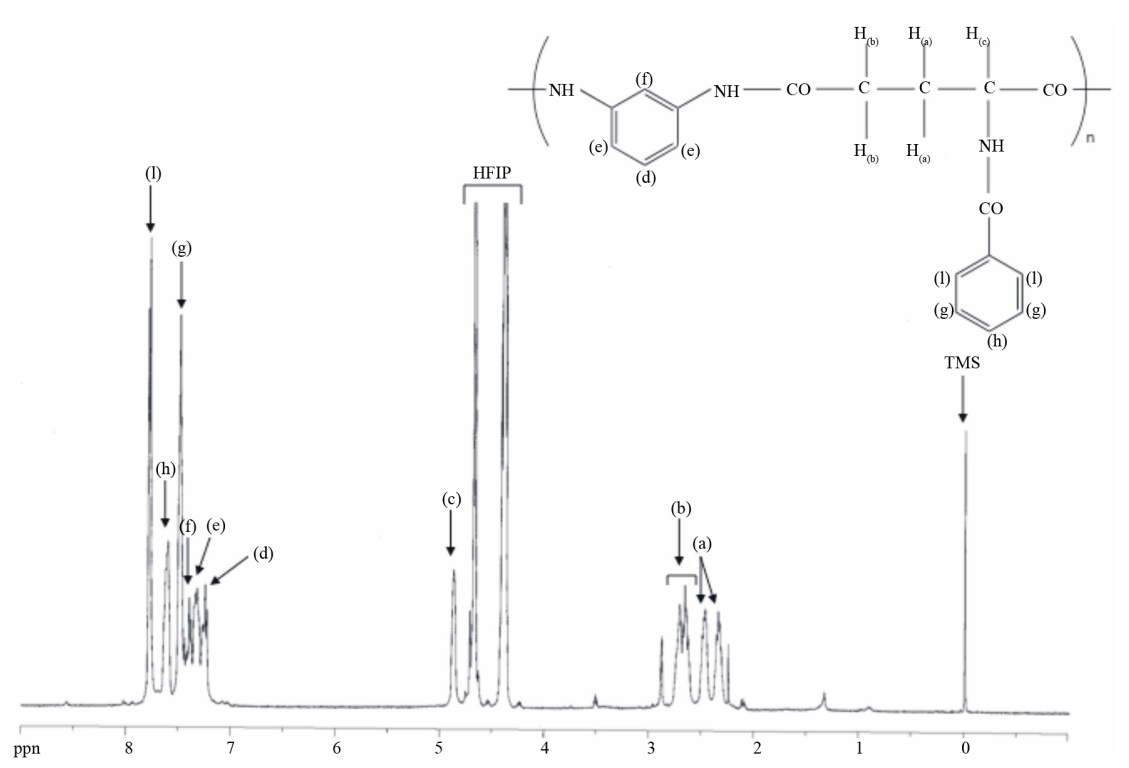

Figure 2. ${ }^{1} \mathrm{H}-\mathrm{NMR}$ spectrum of polyamide from 1,3-PDA and Benzoy-L-Glu-OH (500 MHz, HFIP-d $_{2}$ ).

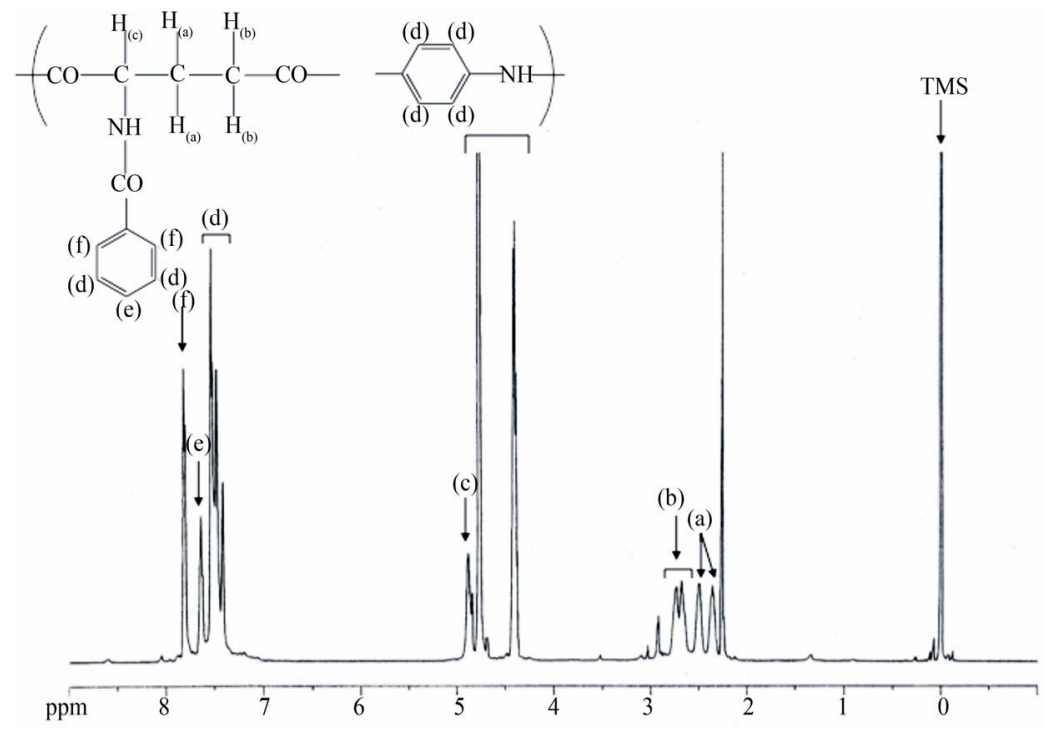

Figure 3. ${ }^{1} \mathrm{H}$-NMR spectrum of polyamide from 1,4-PDA and Benzoy-L-Glu-OH (500 MHz, HFIP-d d $_{2}$. 


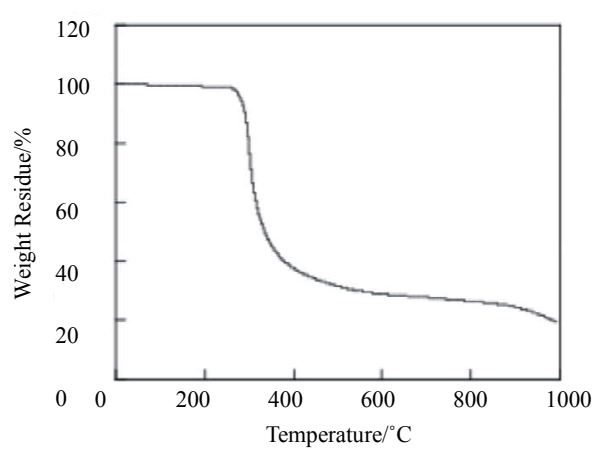

(a)

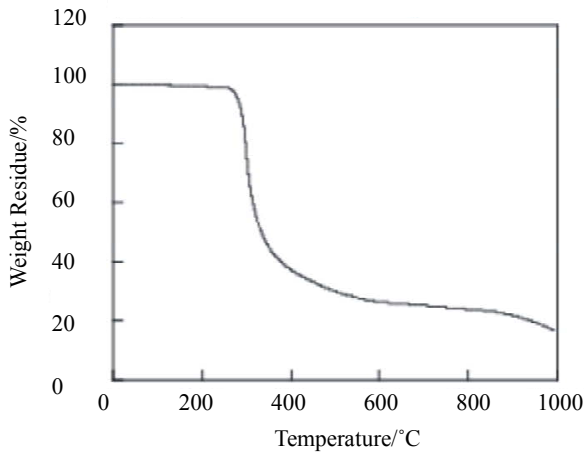

(b)

Figure 4. TGA curves of chiral polyamides consisting of glutamyl residue as a diacid component. $\left(\mathrm{Heating}^{\mathrm{rate}}, \mathbf{1 0}^{\circ} \mathrm{C} \cdot \mathrm{min}^{-1}\right.$.); (a) 1,2-PDA-Benzoyl-L-Glu; (b) 1,4-PDA-Benzoyl-L-Glu.

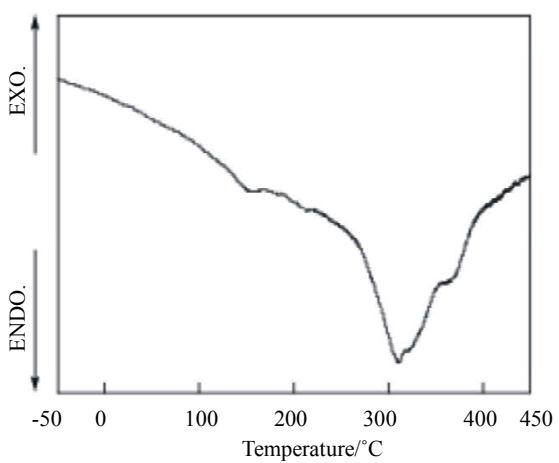

(a)

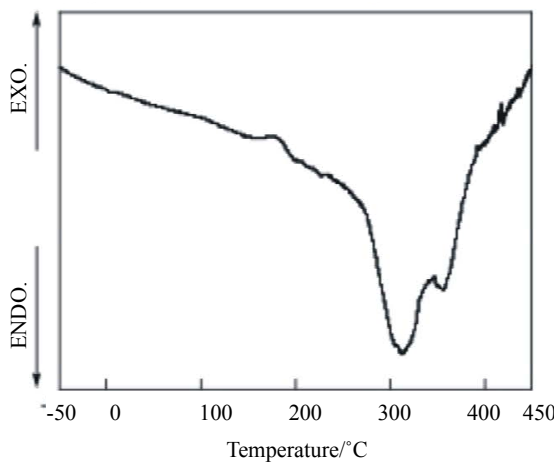

(b)

Figure 5. DSC curves of chiral polyamides consisting of glutamyl residue as a diacid component. (Heating rate, $20^{\circ} \mathrm{C} \mathrm{min}{ }^{-1}$; $\mathrm{N}_{2}$ flow, $50 \mathrm{~cm}^{3} \mathrm{~min}^{-1}$.); (a) 1,3-PDA-Benzoyl-L-Glu; (b) 1,4-PDA-Benzoyl-L-Glu.

Table 1. Polycondensation reaction of 1,3-phenylendiamine (1,3-PDA) and Benzoyl-L-Glu-OH by means of triphenyl phosphite ${ }^{\mathrm{a}}$.

\begin{tabular}{|c|c|c|c|c|c|c|c|c|}
\hline Exp. & Monomer Conc. ${ }^{\text {b }}$ & PDA & Benzoyl-L-Glu-OH & Triphenyl Phosphite & NMP/Py & $\mathrm{LiCl}$ & Yield & $\eta_{\text {inch }}^{\mathrm{c}}$ \\
\hline No. & $\mathrm{mol} \cdot \mathrm{dm}^{-3}$ & $\mathrm{G}(\mathrm{mol})$ & $\mathrm{G}(\mathrm{mol})$ & $\mathrm{G}(\mathrm{mol})$ & $\mathrm{cm}^{3} / \mathrm{cm}^{3}$ & $\mathrm{~g}$ & $\mathrm{~g}(\%)$ & $\mathrm{g}^{-1} \mathrm{~cm}^{3}$ \\
\hline 1 & $3.00 \times 10^{-1}$ & $0.3245\left(3.000 \times 10^{-3}\right)$ & $0.7538\left(3.000 \times 10^{-3}\right)$ & $1.8626\left(6.003 \times 10^{-3}\right)$ & $8 / 2$ & 0.400 & $0.823(84.8)$ & 60 \\
\hline 3 & $4.00 \times 10^{-1}$ & $0.3245\left(3.000 \times 10^{-3}\right)$ & $0.7538\left(3.000 \times 10^{-3}\right)$ & $1.8621\left(6.001 \times 10^{-3}\right)$ & $6 / 1.5$ & 0.300 & $0.795(81.9)$ & 83 \\
\hline 3 & $5.00 \times 10^{-1}$ & $0.3245\left(3.000 \times 10^{-3}\right)$ & $0.7538\left(3.000 \times 10^{-3}\right)$ & $1.8628\left(6.004 \times 10^{-3}\right)$ & $4.8 / 1.2$ & 0.240 & $0.812(83.7)$ & 56 \\
\hline
\end{tabular}

${ }^{\mathrm{a}}$ Polymerization temp., $80^{\circ} \mathrm{C}$; polymerization time, $3 \mathrm{~h}$; ${ }^{\mathrm{b}}$ Monomer Conc. $=[1,3-\mathrm{PDA}]_{0}=[\text { Benzoyl-L-Glu-OH }]_{0} ;{ }^{\mathrm{c}} \mathrm{Measured}$ at a concentration of $5.0 \times 10-3 \mathrm{~g}$ $\mathrm{cm}^{-3}$ in HFIP at $25^{\circ} \mathrm{C}$.

to be $152.7^{\circ} \mathrm{C}$ for $1,3-P D A-B e n z o y l-L-G l u$ and $155.2^{\circ} \mathrm{C}$ for 1,4-PDA-Benzoyl-L-Glu, respectively, whereas that for DADPM-Benzoyl-L-Glu to be $91.4^{\circ} \mathrm{C}$ [13]. The drastic increment of glass transition temperature is also due to the adoption of more rigid diamine monomer of 1,3PDA or 1,4-PDA instead of DADPM.

\subsection{Mechanical Properties}

Mechanical properties of the present polyamides were studied. The strain-stress curves of those membranes are given in Figure 6. Mechanical properties for the present membranes are summarized in Table 3 together with common polymers [24].

\subsection{Chiroptical Properties}

The optical rotations $\left([\alpha]_{\mathrm{D}}\right)$ of two types of chiral polyamide are summarized in Table 4 , together with that of the corresponding diacid monomer, Benzoyl-L-Glu-OH. The results in Table 4 revealed that optically active polyamides were successfully prepared via polycondensation reaction activated by TPP. Those polyamides were expected to show chiral recognition ability from the facts 
Table 2. Polycondensation reaction of 1,4-phenylendiamine (1,4-PDA) and Benzoyl-L-Glu-OH by means of triphenyl phosphite ${ }^{\mathrm{a}}$.

\begin{tabular}{|c|c|c|c|c|c|c|c|c|}
\hline $\begin{array}{l}\text { Exp. } \\
\text { No. }\end{array}$ & $\begin{array}{l}\text { Monomer Conc. } \\
\text { mol dm }\end{array}$ & $\begin{array}{l}\text { PDA } \\
\mathrm{g}(\mathrm{mol})\end{array}$ & $\begin{array}{c}\text { Benzoyl-L-Glu-OH } \\
\text { g (mol) }\end{array}$ & $\begin{array}{l}\text { Triphenyl Phosphite } \\
\text { g (mol) }\end{array}$ & $\begin{array}{l}\mathrm{NMP} / \mathrm{Py} \\
\mathrm{cm}^{3} / \mathrm{cm}^{3}\end{array}$ & $\begin{array}{c}\mathrm{LiCl} \\
\mathrm{g}\end{array}$ & $\begin{array}{l}\text { Yield } \\
\mathrm{g}(\%)\end{array}$ & $\begin{array}{r}\eta_{\text {inch }}{ }^{\mathrm{c}} \\
\mathrm{g}^{-1} \mathrm{~cm}^{3}\end{array}$ \\
\hline 21 & $3.00 \times 10^{-1}$ & $0.3245\left(3.000 \times 10^{-3}\right)$ & $0.7538\left(3.000 \times 10^{-3}\right)$ & $1.8617\left(6.000 \times 10^{-3}\right)$ & $8 / 2$ & 0.400 & $0.883(91.0)$ & 62 \\
\hline 22 & $4.00 \times 10^{-1}$ & $0.3245\left(3.000 \times 10^{-3}\right)$ & $0.7538\left(3.000 \times 10^{-3}\right)$ & $1.8621\left(6.001 \times 10^{-3}\right)$ & $6 / 1.5$ & 0.300 & $0.891(91.8)$ & 64 \\
\hline 23 & $5.00 \times 10^{-1}$ & $0.3245\left(3.000 \times 10^{-3}\right)$ & $0.7538\left(3.000 \times 10^{-3}\right)$ & $1.8621\left(6.001 \times 10^{-3}\right)$ & $4.8 / 1.2$ & 0.240 & $0.899(92.7)$ & 56 \\
\hline
\end{tabular}

${ }^{a}$ Polymerization temp., $80^{\circ} \mathrm{C}$; polymerization time, $3 \mathrm{~h} ;{ }^{b}$ Monomer Conc. $=[1,4-\mathrm{PDA}]_{0}=[\text { Benzoyl-L-Glu-OH }]_{0} ;{ }^{\mathrm{c}}$ Measured at a concentration of $5.0 \times 10-3$ $\mathrm{g} \mathrm{cm}-3$ in HFIP at $25^{\circ} \mathrm{C}$.

Table 3. Ultimate mechanical properties of chiral polyamides.

\begin{tabular}{|c|c|c|c|}
\hline $\begin{array}{l}\text { Membrane } \\
\text { (Film) }\end{array}$ & $\begin{array}{l}\text { Tensile strength } \\
\text { at break/MPa }\end{array}$ & $\begin{array}{l}\text { Elongation } \\
\text { at break/\% }\end{array}$ & $\begin{array}{c}\text { Tensile modulus/ } \\
\qquad \mathrm{GPa}\end{array}$ \\
\hline 1,3-PDA-Benzoyl-L-Glu & 37 & 2.7 & 1.4 \\
\hline 1,4-PDA-Benzoyl-L-Glu & 36 & 6.4 & 0.73 \\
\hline Polystyrene $^{\mathrm{a}}$ & 50 & 2.5 & 3.4 \\
\hline Poly(methyl methacrylate) ${ }^{\mathrm{a}}$ & 65 & 10.0 & 3.2 \\
\hline Nylon $66^{\mathrm{a}}$ & 80 & 200.0 & 2.0 \\
\hline Nylon $6^{\mathrm{a}}$ & 75 & 300.0 & 1.9 \\
\hline
\end{tabular}

${ }^{\mathrm{a}}$ Cited from ref. 24.

Table 4. Specific rotations of diacid monomers and chiral polyamides.

\begin{tabular}{cc}
\hline & {$[\alpha]_{\mathrm{D}}$} \\
\cline { 2 - 2 } $\operatorname{deg~cm}^{2} \mathrm{~g}^{-1}$ \\
\hline Benzoyl-L-Glu-OH \\
\hline 1,3-PDA-Benzoyl-L-Glu \\
1,4-PDA-Benzoyl-L-Glu
\end{tabular}

${ }^{\mathrm{a}}$ in DMF, $\mathrm{c}=5.00 \mathrm{~g} \mathrm{dL}^{-1}, \mathrm{~L}=10 \mathrm{~cm}$; ${ }^{\text {in }} \mathrm{DMF}, \mathrm{c}=1.00 \mathrm{~g} \mathrm{dL}^{-1}, \mathrm{~L}=10 \mathrm{~cm}$.

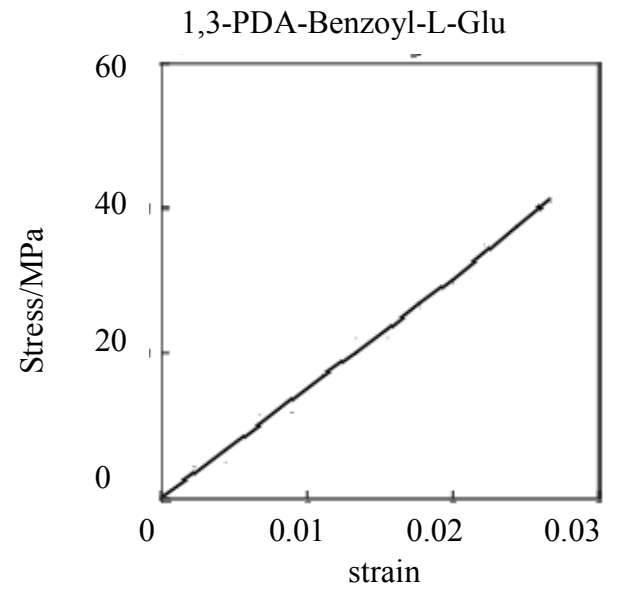

(a)

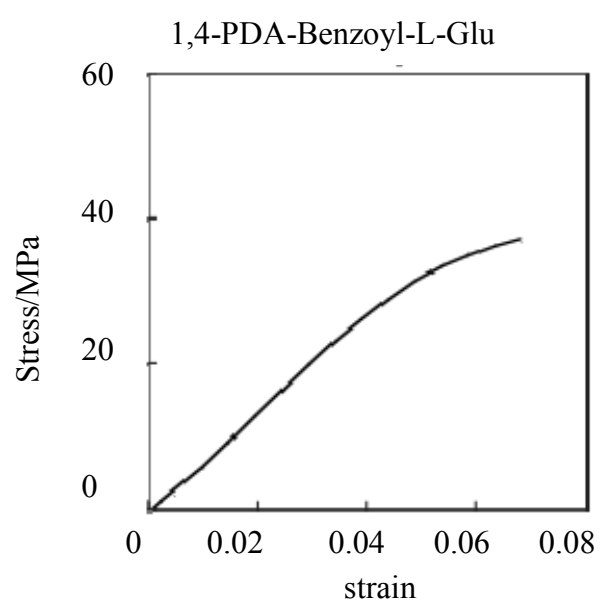

(b)

Figure 6. Strain-stress curves of chiral polymaides consisting of Benzoyl-L-Glu as a diacid component. 


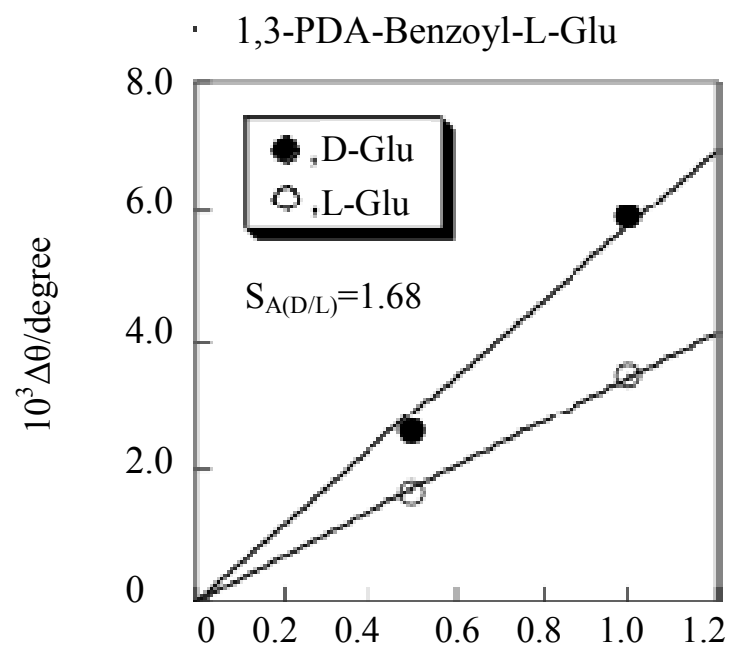

(a)

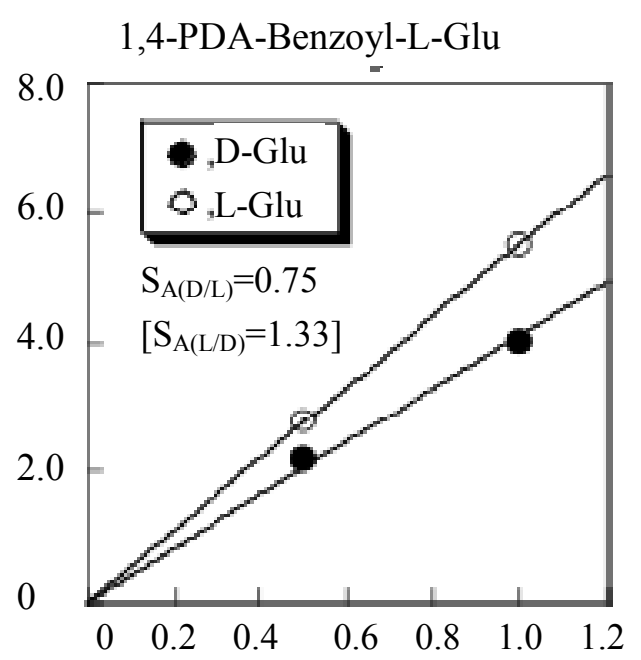

(b)

Figure 7. Adsorption isotherms of D-Glu and L-Glu on the chiral polyamide films at $27^{\circ} \mathrm{C}$.

that there can be found asymmetric environments in those polyamides.

\subsection{Adsorption Selectivity}

As described in the last part in the previous section, those polyamides were expected to show chiral recognition ability. To this end, chiral recognition ability of those two types of polyamide was studied by surface plasmon resonance (SPR) spectroscopy. Compared with usual adsorption experiments for adsorption selectivity, SPR spectroscopy provides a rapid and facile evaluation method. The observed shift in the incidence angle $(\Delta \theta)$ was plotted as a function of the substrate concentration and shown in Figure 7. Apparent adsorption isotherms of D-Glu and L-Glu for those two types of polyamide gave straight lines passing through origin, implying that both D-Glu and L-Glu were non-specifically adsorbed on those chiral polyamide films. The experiment for selective adsorption of D-Glu and L-Glu from racemic mixture of Glu cannot be conducted by SPR spectroscopy. The adsorption selectivity was calculated by the following Equation [24]:

$S_{A(\mathrm{i} / \mathrm{j})}=\Delta \theta_{\mathrm{i}} / \Delta \theta_{\mathrm{j}}$

The subscripts D and L refer to the D-isomer and the L-isomer of Glu, respectively. There are two situations; i $=\mathrm{D}, \mathrm{j}=\mathrm{L}$ and $\mathrm{i}=\mathrm{L}, \mathrm{j}=\mathrm{D}$.

As can be seen in Figure 7, 1,3-PDA-Benzoyl-L-Glu adsorbed D-Glu in preference to L-Glu and the adsorption selectivity toward D-Glu was determined to be 1.68. Contrary to this, L-Glu was preferentially incorporated into 1,4-PDA-Benzoyl-L-Glu and the adsorption selectivity toward L-Glu was determined to be 1.33 . In the previous study, DADPM-Benzoyl-L-Glu showed adsorption selectivity toward D-Glu and the adsorption selectivity toward the D-isomer was determined to be 1.64 [13]. Even though 1,4-PDA-Benzoyl-L-Glu was prepared from same diacid component of Benzoyl-L-Glu-OH, it showed the opposite adsorption selectivity. This difference might be due to the fact that 1,4-PDA-Benzoyl-L-Glu consisted of 1,4-PDA as a diamine component.

From the results of adsorption study, the present chiarl polyamides are expected to show chiral separation ability as a form of membrane, adsorbent, stationary phase, and so forth.

\section{Conclusion}

Polyamides with chiral environment were obtained from aromatic diamine, 1,3-phenylenediamine (1,3-PDA) or 1,4-phenylenediamine (1,4-PDA), and N- $\alpha$-benzoyl-Lglutamic acid (Benzoyl-L-Glu). The optical rotation $\left([\alpha]_{\mathrm{D}}\right)$ for 1,3-PDA-Benzoyl-L-Glu was determined to be 3.7 $\operatorname{deg} \mathrm{cm}^{2} \mathrm{~g}^{-1}$, while that for 1,4-PDA-Benzoyl-L-Glu to be $9.7 \mathrm{deg} \mathrm{cm}^{2} \mathrm{~g}^{-1}$. 1,3-PDA-Benzoyl-L-Glu showed adsorption selectivity toward D-Glu and its adsorption selectivity was determined to be 1.68 . Contrary to this, $1,4-$ PDA-Benzoyl-L-Glu showed adsorption selectivity toward L-Glu and the adsorption selectivity toward L-Glu was determined to be 1.33 . From those results, those two types of chiral polyamide are expected to applicable to chiral separation or chiral recognition.

\section{REFERENCES}

[1] D. Voet and J. G. Voet, "Biochemistry," Wiley, New York, 1990.

[2] T. McKee and J. R. McKee, "The Molecular Basis of Life," 3rd Edition, WCB/McGraw-Hill, Boston, 2003.

[3] C. A. M. Afonso and J. G. Grespo, "Recent Advances in Chiral Resolution through Membrane-Based Approaches," 
Angewandte Chemie International Edition, Vol. 43, No. 10, 2004, pp. 5293-5295. doi:10.1002/anie.200460037

[4] N. M. Maier and W. Lindner, "Chiral recognirion application of molecularly imprinted polymers: A critical reciew," Analytical and Bioanalytical Chemistry, Vol. 389, No. 2, 2007, pp. 377-397. doi:10.1007/s00216-007-1427-4

[5] R. Xie, L.-Y. Chu and J.-G. Deng, "Membranes and Membrane Processes for Chiral Resolution," Chemical Society Reviews, Vol. 37, No. 6, 2008, pp. 1243-1263. doi:10.1039/b713350b

[6] A. Higuchi, M. Tamai, Y.-A. Ko, Y. Tagawa, Y.-H. Wu, B. D. Freeman, J.-T. Bing, Y. Chang and Q.-D. Ling, "Polymeric Membranes for Chiral Separation of Pharmaceuticals and Chemicals," Polymer Reviews, Vol. 50, No. 2, 2010, pp. 113-143. doi:10.1080/15583721003698853

[7] M. Yoshikawa, J. Izumi, T. Kitao and S. Sakamoto, "Molecularly Imprinted Polymeric Membranes Containing SISE Derivatives for Optical Resolution of Amino Avids," Macromolecules, Vo. 29, No. 25, 1996, pp. 81978203. doi: $10.1021 / \mathrm{ma} 951716 \mathrm{v}$

[8] M. Yoshikawa and J. Izumi, "Chiral Recognition Sites Converted from Tetrapeptide Derivatives Adopting Racemates as Print Moleciles," Macromolecular Bioscience, Vol. 3, No. 9, 2003, pp. 487-498.

doi:10.1002/mabi.200350016

[9] M. Yoshiakwa, Y. Nagai, K. Moriguchi and S. Hiraoka, "Chiral Recogniiton Ability of Oligopeptide Derivatives Consisting of Glutamyl Residues," Journal of Applied Polymer Science, Vol. 95, No. 6, 2005, pp. 1302-1309. doi:10.1002/app.21307

[10] Y. Sueyoshi, C. Fukushima and M. HYoshikawa, "Molecularly Imprinted Nanofiber Membranews from Cellulose Acetate Aimed for Chiral Separation," Journal of Membrane Science, Vol. 357, No. 1-2, 2010, pp. 90-97. doi:10.1016/j.memsci.2010.04.005

[11] Y. Sueyoshi, A. Utsunomiya, M. Yoshikawa, G. P. Robertson and M. D. Guiver, "Chiral Separation with Molecularly Imprinted Polysulfone-Aldehyde Derivatized Nanofiber Membranes," Journal of Membrane Science, Vol. 401-402, 2012, pp. 89-96. doi:10.1016/j.memsci.2012.01.033

[12] M. Nakagawa, Y. Ikeuchi and M. Yoshikawa, "Chiral Separation of Racemic Amino Acids with Novel Polyamide Having N- $\alpha$-Acetyl-L-glutamyl Residue as a Diacid Component," Polymer, Vol. 49, No. 21, 2008, pp. 4612-4619. doi:10.1016/j.polymer.2008.08.018

[13] Y. Ikeuchi, M. Nakagawa, M. Yoshikawa, H. Yoshida and S. Sakurai, "Chiral Polyamides Consisting of N- $\alpha$ -
Benzoyl-L-Glutamic Acid as a Diacid Component," Journal of Polymer Science Part A: Polymer Chemistry, Vol. 47, No. 10, 2009. pp. 2530-2538. doi:10.1002/pola.23335

[14] T. Hashimoto and M. Yoshikawa, "Chiral Separation of Racemic Mixtures with Chiral Polyamide Membranes Containing Aspartyl Residues in their Main Chains," Current Nanoscience, Vol. 7, No. 6, 2011, pp. 915-924. doi:10.2174/157341311798220664

[15] M. Hatanaka, Y. Nishioka and M. Yoshikawa, "Polyurea with L-Lysinyl Residues as Components: Application to Membrane Separation of Enantiomers," Macromolecular Chemistry and Physics, Vol. 212, No. 13, 2011, pp. 13511359. doi:10.1002/macp.201100054

[16] H. Mizushima, M. Yoshikawa, G. P. Robertson and M. D. Guiver, "Optical Resolution Membranes from Polysulfone Bearing Alanine Derivatives as Chiral Selectors," Macromolecular Materials and Engineering, Vol. 296, No. 6, 2011, pp. 562-567. doi:10.1002/mame.201000396

[17] M. Yoshikawa, M. Maruhashi, Y. Iwamoto and N. Ogata, "Optical Resolution of Racemic Amino Acids through DNA-Poly(4-vinylbenzoyl)trimethylammonium Polyion Complec Membranes," Polymer Journal, Vol 39, No. 11, 2007, pp. 1193-1198. doi:10.1295/polymj.PJ2007080

[18] Y. Sueyoshi, T. Hahsimoto, M. Yoshikawa and K. Watanabe, "Transformation of Intact Chicken Feathers into Chiral Separation Membranes," Waste Biomass Valor, Vol. 2, No. 3, 2011, pp. 303-307. doi:10.1007/s12649-011-9066-6

[19] Y. Sueyoshi, T. Hahsimoto, M. Yoshikawa and S. Ifuku, "Chitin Nanofiber Membranes for Chiral Separation," Journal of Sustainable Agriculture, Vol. 1, No. 1, 2012, pp. 42-47.

[20] "Dictionary of Organic Compounds," 4th Edition, Maruzen, Tokyo, 1965, p. 2685.

[21] "Beilsteins Handbuch der Organischen Chemie," 13 IV. Springer-Verlag, Berlin, 1973, p.104.

[22] J. A. Riddick, W. B. Bunger and T. K. Sakano, "Organic Solvents," 4th Edition, John Wiley \& Sons, New York, 1986.

[23] D. J. Walton and J. P. Lorimer, "Polymers," Oxford University Press, Oxford, 2000.

[24] K. Taniwaki, A. Hyakutake, A. Aoki, M. Yoshikawa, M. D. Guiver and G. P. Robertson, "Evaluation of the Recognition Ability of Molecularly Imprinted Materials by Surface Plasmon Resonance (SPR) Spectroscopy," Analytica Chimica Acta, Vol. 489, No. 2, 2003, pp. 191-198. doi:10.1016/S0003-2670(03)00760-8 